\title{
Review: continuous nasogastric milk feeding leads to a longer time to reach full feeds in premature infants $<1500 \mathrm{~g}$
}

Premji S, Chessell L. Continuous nasogastric milk feeding versus intermittent bolus milk feeding for premature infants less than 1500 grams. Cochrane Database Syst Rev 2001;(1):CD001819 (latest version Nov 22 2001).

\section{QUESTION: In premature infants weighing $<1500 \mathrm{~g}$, how effective is continuous compared with intermittent bolus nasogastric milk feeding?}

\section{Data sources}

Studies were identified by searching Medline, CINAHL, HealthSTAR, and the Cochrane Controlled Trials Register up to June 2000; and by reviewing abstracts, conference proceedings, and references from relevant publications.

\section{Study selection}

Studies were selected if they were randomised or quasirandomised controlled trials that enrolled infants $<1500$ g with no major congenital anomalies that might interfere with feeding tolerance; evaluated continuous nasogastric compared with intermittent bolus tube feedings of breast milk or formula; and assessed days to full feeds, feeding tolerance, time to regain birth weight, somatic growth, days to discharge, or complications such as necrotising enterocolitis and apnoea.

\section{Data extraction}

2 reviewers independently extracted data on methodological quality, patient characteristics, intervention type, and outcomes.

\section{Main results}

5 studies met the selection criteria and were included in the review. Meta-analysis of data from 4 trials showed that it took infants longer to reach full feeds when fed by continuous tube feeding than with intermittent bolus tube feeding (table). 3 individual trials reporting on feeding intolerance each found no difference between treatment groups. No differences existed between the 2 groups for time to regain birth weight (3 trials), weight gain (2 trials), length gain (3 trials), head circumference gain (3 trials), change in triceps skinfold thickness (2

Continuous v intermittent bolus milk feeding in premature infants $<1500 \mathrm{~g}$

\begin{tabular}{lc} 
Outcomes & $\begin{array}{c}\text { Weighted mean } \\
\text { difference }(95 \% \mathrm{Cl})\end{array}$ \\
\hline Days to full feeds & $3.0(0.7$ to 5.2$) \dagger$ \\
\hline Days to regain birth weight & $-0.6(-1.8$ to 0.6$)$ \\
\hline Weight gain $(\mathrm{g} / \mathrm{kg} / \mathrm{d})$ & $-1.1(-2.3$ to 0.03$)$ \\
\hline Length gain $(\mathrm{cm} / \mathrm{wk})$ & $0.1(-0.01$ to 0.2$)$ \\
\hline Head circumference gain $(\mathrm{cm} / \mathrm{wk})$ & $-0.03(-0.1$ to 0.04$)$ \\
\hline Triceps skinfold thickness $(\mathrm{mm} / \mathrm{wk})$ & $0(-0.1$ to 0.1$)$ \\
\hline Days to discharge & $-1.9(-8.3$ to 4.4$)$ \\
\hline †Statistically significant. &
\end{tabular}

trials), days to discharge (2 trials) (table), necrotising enterocolitis ( 4 trials, \{relative risk reduction 4\%, 95\% CI $-90 \%$ to $\left.51 \%\}^{*}\right)$, or apnoea (2 trials).

\section{Conclusions}

Continuous nasogastric milk feeding leads to a longer time to reach full feeds than does intermittent bolus milk feeding in premature infants $<1500 \mathrm{~g}$. No other differences existed between the 2 treatment groups.

*Numbers calculated from data in article.

\section{COMMENTARY}

This review by Premji and Chessell has systematically identified, selected, evaluated, and analysed existing studies of infants $<1500 \mathrm{~g}$ fed by continuous versus intermittent bolus milk feedings. The discussion of the risks and benefits of continuous versus bolus feedings is thought provoking for clinicians. Although the clinical effect is unclear, additional theoretical concerns about continuous feedings include the loss of fat and protein nutrients in the tubing, risk of bacterial proliferation, and the potential for toxic effects from prolonged light exposure and resultant lipid perioxidation. ${ }^{1-4}$

The quality of this review is influenced by the individual studies, which had small sample sizes, inadequate numbers for subgroup analysis, and key differences in the initiation, advancement, and withholding of feedings. Clinically relevant outcome data (days to full feedings and growth) are difficult to interpret given differences in the definition of full feedings ( $70 \mathrm{kcal} / \mathrm{kg}$ to $100 \mathrm{kcal} / \mathrm{kg}$ ). It is unclear whether differences in growth (or lack thereof) can be attributed to the feeding method or to the targeted caloric intake. Necrotising enterocolitis was identified as an outcome measure, but none of the studies was sufficiently powered to detect changes in this infrequent but clinically important event.

This review shows the wide variation in feeding practices, driven to a large degree by individual clinician preferences; however, it fails to define the premature infant's tolerance of continuous versus bolus feedings. The authors' conclusion that recommendations about preferred feeding practices cannot be made at this time is sound.

The methodological perils of feeding studies are clear. The large number of variables that should be controlled in future clinical trials is illustrative. At a minimum, studies should strive for the following: randomisation; stratification of groups by feeding type; power analysis to identify a sample size sufficient to detect differences in outcome variables of interest (eg, necrotising enterocolitis); control for age of feeding initiation, rate of bolus feedings, in situ versus intermittent tube placement, non-nutritive sucking, and illness severity; and adoption of strict protocols for withholding feedings.

Madge E Buus-Frank, RNC, ARNP, MS Editor in Chief Advances in Neonatal Care: The Official Journal of the National Association of Neonatal Nurses Hanover, New Hampshire, USA

1 Stocks RJ, Davies DP, Allen F, et al. Loss of breast milk nutrients during tube feeding. Arch Dis Child 1985;60:164-6.

2 Lavine M, Clark RM. The effect of short-term refrigeration of milk and addition of breast milk fortifier on delivery of lipids during tube feedings. J Pediatr Gastroenterol Nutr 1989;8:496-9.

3 Dodd V, Froman R. A field study of bacterial growth in continuous feedings in the newborn intensive care unit. Neonatal Netw 1991;9:17-21.

4 van Zoeren-Grobben D, Moison RM, Ester WM, et al. Lipid perioxidation in human milk and infant formula: effect of storage, tube feeding and exposure to phototherapy. Acta Paediatr 1993;82:645-9. 